language. I would like to thank Dr, Banssillon for bringing his article to our attention.

There are several differences between his report and ours. Professor Banssillon makes no comment as to whether his study was in any way blinded (single-blinded or double-blinded) and whether or not a controd group was included. Secondly it appears that the technique and do sage of injection varied in the earlier study. Our patients were given $20 \mathrm{ml}$ of either normal saline or 0.25 per cent bupivacaine in a blinded fashion, whereas in Banssillon's study he used bupivacaine 0.5 per cent with epinephrine, in a dose of $1.5 \mathrm{mg} \cdot \mathrm{kg}^{-1}$ in varying volumes of 30-60 $\mathrm{ml}$. We recorded no cases of lateral femoral cutanew rerve block.

Both articles serve to reinforce the conclusion that it is possible to provide good postoperative analgesia with femoral nerve blocks for patients undergoing open knee surgery.

Geraint Lewis MD FRCPC

Department of Anaesthesia

Ottawa Civic Hospital

1053 Carling Avenue

Ontawa, Ontario

KIY 4E9

\section{Suspected tumor embolism as a cause of arterial line dysfunction}

\section{To the Editor:}

Systemic arterial embolization of carcinoma of the lung is a rare phenomenon, with 28 cases having been reported previously. ${ }^{\prime}$ Of these, only two cascs involved embolization to the axillary artery. ${ }^{2}$

Our patient, a 72-year-old male, presented with a two-week history of right-sided pleuritic chest pain. A chest $x$-ray revealed a right hilar mass. Past history included 50 pack-years of cigarette smoking and hypertension treated with a triamterene-hydrochlorothiazide combination and metoprolol. There was no history of ischaemic heart disease or diabetes mellitus.

Physical examination was unremarkable, except for diminished breath sounds on the right side. An Allen's test revealed brisk ulnar collateral flow bilaterally. FEV, was $2.4 \mathrm{~L}$ with an FVC of $3.15 \mathrm{~L}$.

Anuesthesia was induced with thiopentone, and maintained with isoflurane in 100 per cent oxygen and intermittent bolus doses of fentanyl. Intubation with a 39 french left sided double lumen tube was facilitated by the administration of pancuronium.

During dissection around the hilum of the right lung, the surgeon noted that tumour was extending into one of the pulmonary veins. Shortly afterwards, the artcrial tracing became flat. On examination, the left radial pulse was absent, and the whole left hand demonstrated poor capillary refill. Heparinized saline flush followed by catheter removal did not result in any improvement.
At the end of the case, the patient was transferred to the Intensive Care Unit. At this point, it was appreciated that the left ulnar, brachial and axillary pulses were absent as well. At approximately the same time as the circulation spontaneously returned to the left hand, the right leg became acutely ischaemic. The patient was returned to the Operating Room and a femoral embolectomy was performed. Fragments of tumour embolus were recovered and the circulation restored. He was again transferred to the Intensive Care Unit. Two hours later, the patient haemorrhaged from the resected pulmonary artery, and could not be resuscitated. At autopsy, no residual tumour fragments could be found.

The loss of radial artery flow in the present case was probably secondary to subclavian or axillary artery tumour embolism. The loss of the other pulses in the left upper extremity and spontaneous return of flow, make other canses less likely. Only two of the cases in the review by Starr $e t$ al. of embolization of bronchogenic carcinoma involved the axillary artery; most emboli migrated to the femoral artery, probably because of the directness of the vascular path.

At autopsy, no evidence of residual tumour in the subclavian or axillary arteries could be found. As the circulation to the hand had spontaneously returned, the obstructive mass had probably fragmented and flowed distally down the aorta during the course of events.

In conclusion, damping of the arterial trace during pulmonary surgery should alert the anaesthetist to the possibility of systemic arterial embolization of bronchogenic carcinoma.

Donald C. Oxom MDCM FRCPC

Department of Anaesthesia and Surgical Intensive Care The Halifax Infirmary Hospita]

Halifax, Nova Scotia

B3J $2 \mathrm{H} 6$

\section{REFERENCES}

1 Starr DS, Lawrie $G M$, Morris GC. Unusual presentation of bronchogenic carcinoma: case report and review of the literature. Cancer 1981;47:398-401.

2 Aylwin JA. Avoidable vaseular spread in rescetion for bronchial carcinoma. Thorax 1951; 6: 250-67.

\section{System for application of PEEP}

To the Editor:

Heving followed the plethora of literature ${ }^{1-3}$ describing various gadgets over the years, I have hesitated adding yet another. However, I believe this brief description of a device composed of readily available materials is an improvement over more complicated "gadgets" accomplish- 


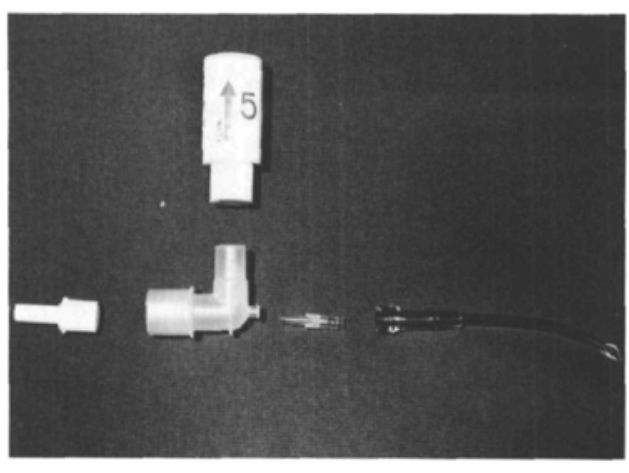

FIGURE System components. See text for details.

ing its purpose quite simply. A PEEP unit to maintain oxygenation of the nondependent lung during surgery can be composed of a Boehringer PEEP valve, Rackow elbow with sampling port, $15 \mathrm{~mm}$ endotracheal tube adapter, oxygen tubing and tank, and optional IV tubing connector (Figure). The device functions well when positioned perpendicular to the surgical table, usually taped in place. An oxygen flow rate of $4 \mathrm{~L} \cdot \mathrm{min}^{-1}$ is usually sufficient to maintain the desired level of PEEP. Periodic inflation of the nondependent lung, if desired, may be performed by occluding the outlet of the PEEP valve with a thumb, similar to operating an Ayre's T-piece. One must, therefore, keep the valve in view so that the outlet is not unintentionally occluded, causing lung expansion into the surgical field, or possible barotrauma. We have used this device for several months and appreciate its utility and simplicity.

\section{Duke B. Weeks MD}

Department of Anesthesia

Bowman Gray School of Medicine

300 South Hawthorne Road

Winston-Salem, NC 27103

\section{REFERENCES}

1 Slinger $P$. Triolet $W$, Chang $M$. CPAP circuit for nonventilated lung during thoracic surgery. Can J Anaesth 1987; 34: 654-5.

2 Hensley FA, Martin F, Skeehan TM. High pressure popoff safety device when using the Bain circuit for CPAP oxygenation during one-lung ventilation. Anesthesiology 1987; 67: 863

3 Alfery $D D$, Benumof $J L_{,}$Trousdale $F R$. Improving oxygenation during one-lung ventilation in dogs: the effects of positive end-expiratory pressure and blood flow restriction to the nonventilated lung. Anesthesiology 1981; 55: $381-5$.

\section{Epidural test dose in obstetrics}

\section{To the Editor}

I greatly admired the comprehensive review of this topic by Drs. Dain, Rolbin and $\mathrm{Hew}^{\prime}$ and the supportive Editorial by Dr. Biehl. ${ }^{2}$ I cannot, however, agree with them regarding the advisability of injecting a test dose before each top-up, especially in the context of topping up conducted by midwives or nurses, and equally definitely in regard to their advocacy of the use of hyperbaric lidocaine for the procedure.

To date (end 1987) we have provided a continuous epidural for over 31,500 labouring mothers. Approximately 126,000 top-ups will have been given by our midwives during the course of these procedures. Throughout this period we have encountered three occasions on which bupivacaine was, subsequent to the first formal dose (always given by the anaesthetist), directly injected into the blood stream (twice) or the CSF (once): incidences respectively of $1: 63,000$ and $1: 126,000$ maintenance top-ups.

The main concern displayed by Dain et al. appears to be with the danger of an inadvertent intrathecal injection, hence their tentative support of the advocacy that 1.5 per cent lidocaine in 7.5 per cent dextrose might be the ideal solution, although currently they consider $30-50 \mathrm{mg}$ in a one to two per cent solution is the test dose of choice. Contrary to the opinions expressed by Dain et al. and by Biehl, I do not believe that the test doses they describe will inevitably afford evidence of an inadvertent intravascular injection. We have encountered cases of peri-oral tingling and other signs which have led us to re-insert the epidural catheter, but our one case of massive intravascular injection of bupivacaine given on the initial injection occurred despite the fact that a test dose of $2 \mathrm{ml}, 1.0$ per cent lidocaine five minutes previously had evoked no response. ${ }^{3}$ Incidentally, I whole-heartedly support those who decline to include epinephrine in the test dose, for reasons well presented by Dain et al.

If, then, hyperbaric lidocaine is to be used to define an inadvertent intrathecal injection, for obvious reasons the mother must be sitting upright during the injection and for several minutes after. Additional to the fuss involved in the inspection, identification (by a witness) and injection of two different solutions, such a procedure will inevitably make considerable extra demands upon midwifery time, as well as causing the mother some stress (she might well have to be helped from, and then back to, a lateral horizontal position). All to avoid a complication with an incidence of one in an eighth of a million.

Again, such a procedure is itself not free from potential hazard. We have administered approximately 1500 spinal anaesthetics in this hospital - admittedly a much smaller 